\title{
Karyological Studies of Thirty Two Varieties of Black Gram (Phaseolus mungo L.)
}

\author{
L. C. Goswami \\ Department of Agricultural Botany, Gauhati University, Gauhati-14, India
}

Received October 13, 1977

The cultivated species of Phaseolus mungo $\mathrm{L}$. has a wide range of varieties with distinct and diffused geographical adaptability. Although the cultivated varieties are known to be diploids $(2 n=22)$, the detail karyotypic studies on a large number of varieties have not been made so far to establish a standardised karyotype for this species except the work of De and Krishnan (1966). The varieties taken up in the investigation are known to have wide differences in their morphology and physiological behaviour. In view of this, a detailed analysis of the somatic chromosomes is considered necessary.

\section{Material and method}

Karyotype of thirty two varieties of black gram was studied from the root tips obtained by germinating the seeds on wet saw dust in petridishes at room temperature. The fresh root tips were collected around 11-30 a.m. The pretreatment in a mixture of water saturated p-dichlorobenzene and aesculin $(1: 1)$ was taken up and the root tips were treated in the mixture for $2 \frac{1}{2}$ hours at $12^{\circ}-13^{\circ} \mathrm{C}$. The tips were washed in water and fixed in propionic ethanol $(1: 2)$ for 40 minutes. Finally the tips were hydrolised by gentle warming for 2-3 seconds in a mixture of $2 \%$ propiono-orcein and $\mathrm{N}-\mathrm{HCl}(9: 1)$ and the material was kept as such for at least 30 minutes. The tips were then squashed in a drop of $45 \%$ propionic acid.

Five to six camera lucida drawings were taken for each variety at the bench level using $15 \times$ ocular and oil immersion objective $100 \times$ from the temporary preparations. Somatic counts and karyotypic formulae were worked out for all the 32 varieties. The position of the centromeres was determined from a comparative study of several metaphase plates. The chromosomes are assigned to different types basing on their relative length, position of centromere and presence or absence of secondary constriction.

The abbreviations used for the purpose are: $\mathrm{M}=$ median, $\mathrm{Sm}=$ submedian, $\mathrm{St}=$ subterminal, $\mathrm{SmSc}=$ secondarily constricted chromosome with submedian primary constriction and $\mathrm{StSc}=$ secondarily constricted chromosome with subterminal primary constriction. Primary constriction was taken as subterminal when arm ratio was $1: 4$ or more than that and as median when arm ratio was less than one third $(1 / 3)$. Chromosome types include also the following: $\mathrm{A}=$ above $2.0 \mu$ to $3.0 \mu, \mathrm{B}=$ above $1.0 \mu$ to $2.0 \mu$ and $\mathrm{C}=$ upto $1 \mu$. The figures in the karyotype formula pertain to the number of pairs of chromosomes. TF \% was calculated 
by the formula given by Huziwara (1962).

An average karyotype was worked out basing on the results of chromosome morphology obtained for all the 32 varieties.
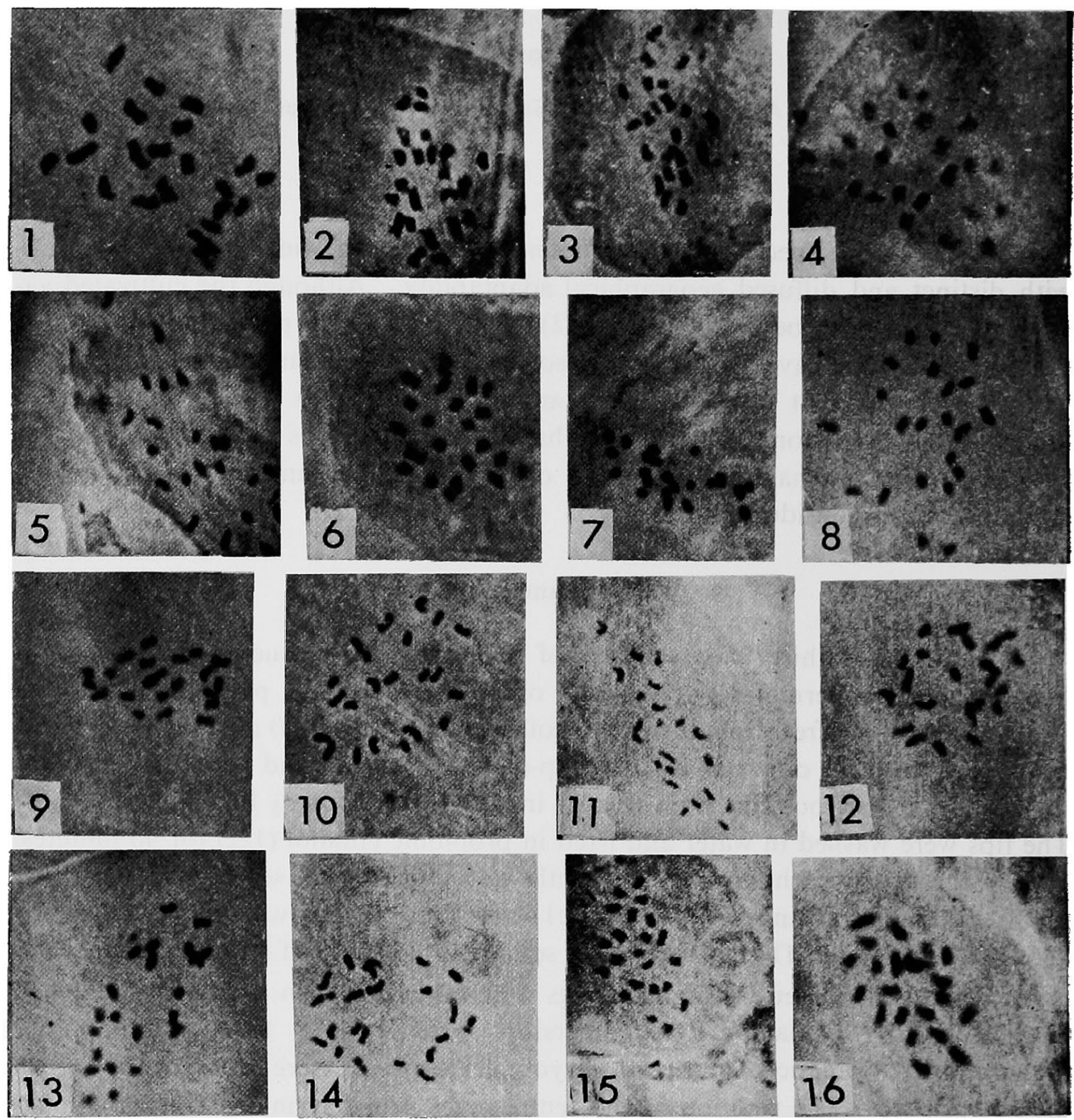

Figs. 1-16, 1. Somatic metaphase plate of variety: T-122. $\times 1500$. 2-16. Somatic metaphase plate of varieties: L41-13, Pusa-1, 91 Local, 9 Local, 15 Local, T-77, No. 40, No.73, Mashl-1, No. 63 , No. 54 , T65, No. 32 , No. 16 and No. 85 respectively. $\times 1000$.

\section{Results}

The cytological study in black gram showed no division before 10-30 a.m. either in winter or summer. The best time of collection of root tip was found around $11-30 \mathrm{a} . \mathrm{m}$.

The chromosome number of all the 32 varieties was found to be $2 n=22$ (Figs. 1-32). All the varieties were characterised by small chromosomes. Out of the 
total of 11 pairs of chromosomes, two pairs were invariably with secondary constrictions either with subterminal or submedian primary constrictions. One pair of chromosomes appeared to be satellited. Based on the analysis of chromosome
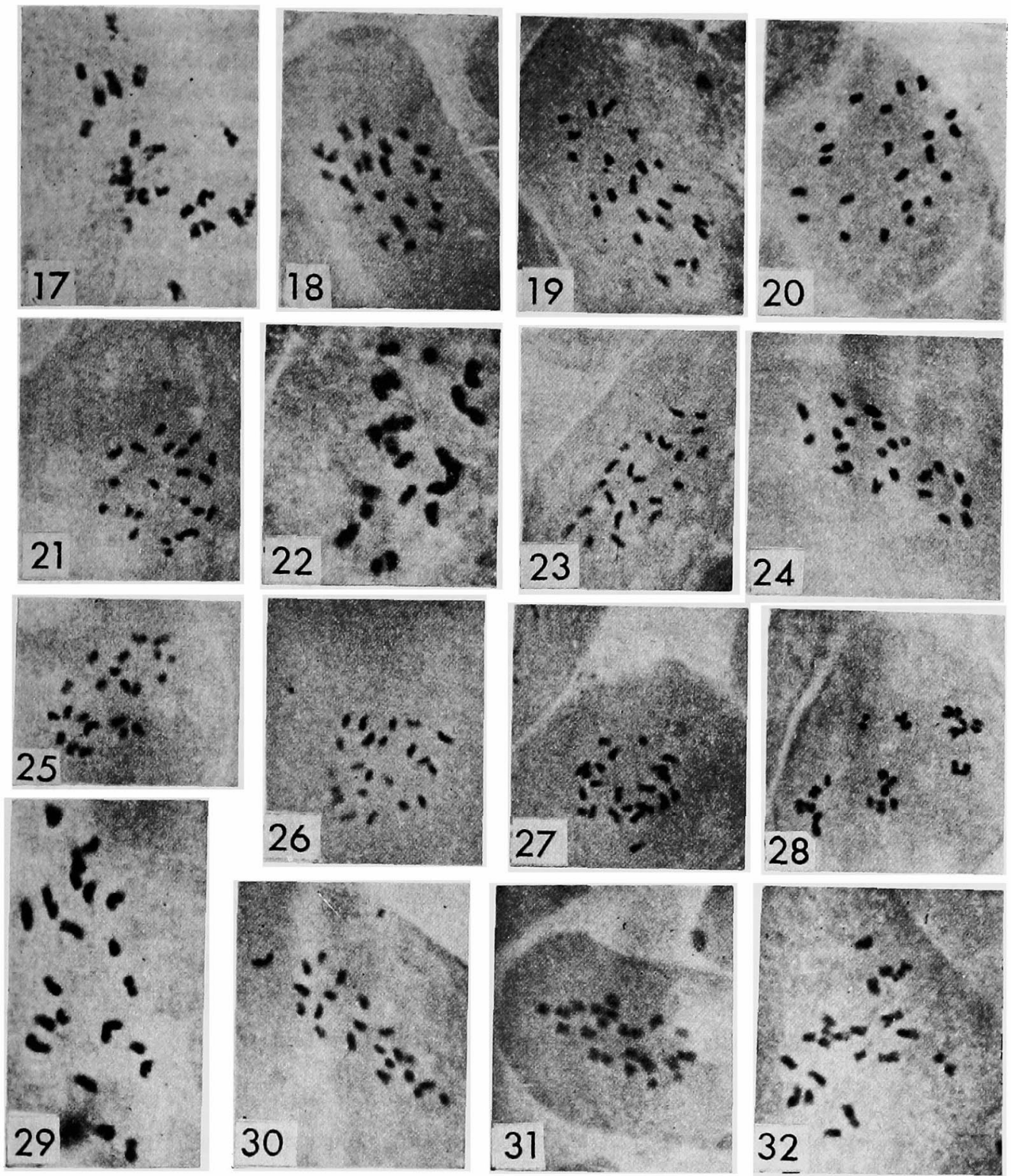

Figs. 17-32. 17, 22,29, and 32: Somatic metaphase plate of varieties: Local Bihar, L35-5, MK 18 , and T9 respectively. $\times 1500.18-21,23-28$, and 30, 31: Somatic metaphase plate of varieties: No. 103, No-100, No. 38, No. 124, 7.9, T130, Mash 48, No. 51, BR61, No. 55, No. 20 and T27 respectively. $\times 1000$.

morphology, the details of karyotype of all the varities are given in Table 1. The idiogram of somatic karyotypes for all the varieties and also the idiogram of an average karyotype are here (Figs. 1a-32a and 33). 
Table 1. Details of karyotype of thirty two varieties of Phaseolus mungo $\mathrm{L}$.

\begin{tabular}{|c|c|c|c|c|c|c|c|c|}
\hline \multirow[b]{2}{*}{$\begin{array}{l}\text { SI. } \\
\text { no. }\end{array}$} & \multirow[b]{2}{*}{$2 n$} & \multicolumn{4}{|c|}{ Type of chromosome } & \multirow{2}{*}{$\begin{array}{l}\text { Total } \\
\text { chromo- } \\
\text { some } \\
\text { length } \\
(\mu)\end{array}$} & \multirow{2}{*}{$\begin{array}{l}\text { Range in } \\
\text { chromosome } \\
\text { length } \\
(\mu)\end{array}$} & \multirow[b]{2}{*}{ T.F. $\%$} \\
\hline & & Median & $\begin{array}{l}\text { Sub- } \\
\text { median }\end{array}$ & $\begin{array}{l}\text { Se } \\
\text { Con } \\
\text { Sm. }\end{array}$ & $\begin{array}{l}\text { ary } \\
\text { tion } \\
\text { St. }\end{array}$ & & & \\
\hline 1. $T-122$ & 22 & 3 & 6 & 1 & 1 & 39.32 & $1.31-2.51$ & 28.89 \\
\hline 2. L41-13 & 22 & 2 & 7 & - & 2 & 38.68 & $1.19-2.39$ & 28.33 \\
\hline 3. Pusa-1 & 22 & 2 & 7 & - & 2 & 37.80 & $1.25-2.38$ & 25.82 \\
\hline 4. 91-Local & 22 & 3 & 6 & 1 & 1 & 30.40 & $1.18-2.10$ & 32.17 \\
\hline 5. 9-Local & 22 & 7 & 2 & 2 & - & 36.56 & $0.99-2.35$ & 34.29 \\
\hline 6. 15-Local & 22 & 9 & - & 2 & - & 33.48 & $1.10-2.06$ & 38.23 \\
\hline 7. $\mathrm{T}-77$ & 22 & 6 & 3 & 2 & - & 26.92 & $0.67-1.68$ & 33.35 \\
\hline 8. No. 40 & 22 & 7 & 2 & 1 & 1 & 29.06 & $0.84-1.83$ & 35.03 \\
\hline 9. No. 73 & 22 & 4 & 5 & - & 2 & 33.72 & $1.04-2.32$ & 31.25 \\
\hline 10. Mashl-1 & 22 & 4 & 5 & - & 2 & 32.44 & $0.95-2.23$ & 30.82 \\
\hline 11. No. 63 & 22 & 2 & 7 & - & 2 & 36.38 & $1.04-2.32$ & 27.15 \\
\hline 12. No. 54 & 22 & 4 & 5 & - & 2 & 36.16 & $1.07-2.41$ & 27.82 \\
\hline 13. T-65 & 22 & 2 & 7 & - & 2 & 36.88 & $1.16-2.65$ & 26.30 \\
\hline 14. No. 32 & 22 & 1 & 8 & - & 2 & 34.06 & $1.22-2.29$ & 26.36 \\
\hline 15. No. 16 & 22 & 5 & 4 & 1 & 1 & 33.36 & $1.08-2.37$ & 29.67 \\
\hline 16. No. 85 & 22 & - & 9 & - & 2 & 35.20 & $1.07-2,32$ & 24.31 \\
\hline $\begin{array}{l}\text { 17. Local } \\
\text { Bihar }\end{array}$ & 22 & 2 & 7 & - & 2 & 38.78 & $1.22-2.78$ & 27.64 \\
\hline 18. No. 103 & 22 & 3 & 6 & 1 & 1 & 35.62 & $1.22-2.17$ & 29.08 \\
\hline 19. No. 100 & 22 & 2 & 7 & - & 2 & 35.76 & $1.04-2.05$ & 26.11 \\
\hline 20. No. 38 & 22 & - & 9 & - & 2 & 34.14 & $0.98-2.23$ & 26.12 \\
\hline 21. No. 124 & 22 & 1 & 8 & - & 2 & 37.32 & $1.25-2,47$ & 25.50 \\
\hline 22. L35-5 & 22 & 2 & 7 & - & 2 & 38.56 & $1.28-2.53$ & 26.24 \\
\hline 23.7 .9 & 22 & 2 & 7 & - & 2 & 35.46 & $1.22-2.50$ & 27.52 \\
\hline 24. $\mathrm{T}-130$ & 22 & 2 & 7 & - & 2 & 35.48 & $1.22-2.38$ & 25.98 \\
\hline 25. Mash-48 & 22 & 1 & 8 & - & 2 & 35.02 & $0.98-2.47$ & 25.64 \\
\hline 26. No. 51 & 22 & 1 & 8 & - & 2 & 33.78 & $1.08-2.21$ & 26.46 \\
\hline 27. BR-61 & 22 & 1 & 8 & - & 2 & 34.70 & $1.07-2.29$ & 25.53 \\
\hline 28. No. 55 & 22 & 5 & 4 & 2 & - & 29.74 & $0.82-2.04$ & 30.26 \\
\hline 29. MK-18 & 22 & 5 & 4 & 1 & 1 & 31.60 & $0.95-2,14$ & 30.88 \\
\hline 30. No. 20 & 22 & 2 & 7 & - & 2 & 35.74 & $1.76-2,17$ & 27.81 \\
\hline 31. $T-27$ & 22 & - & 9 & - & 2 & 36.56 & $1.16-2.38$ & 25.21 \\
\hline 32. $\mathrm{T}-9$ & 22 & 2 & 7 & - & 2 & 37.54 & $1.31-2.35$ & 26.95 \\
\hline
\end{tabular}

The karyotype formula obtained for each variety is given in Table 2.

\section{Discussion}

All the 32 varieties of Phaseolus mungo $L$. are found to have $2 n=22$. This agrees with the reports of Karpechenko (1925) and De and Krishnan (1966). So, the primary base number for this species is confirmed as 11 .

The karyotypic analyses of 32 varieties reveal reasonably significant differences with regard to chromosome length, position of primary constriction and $\mathrm{TF} \%$. $39.32 \mu$ is the maximum total chromosome length and the minimum is $26.92 \mu$. A large number of varieties (17 numbers) have been noted within the close range of total chromosome length of $35 \mu$ to $37.54 \mu$. The study of the range in 


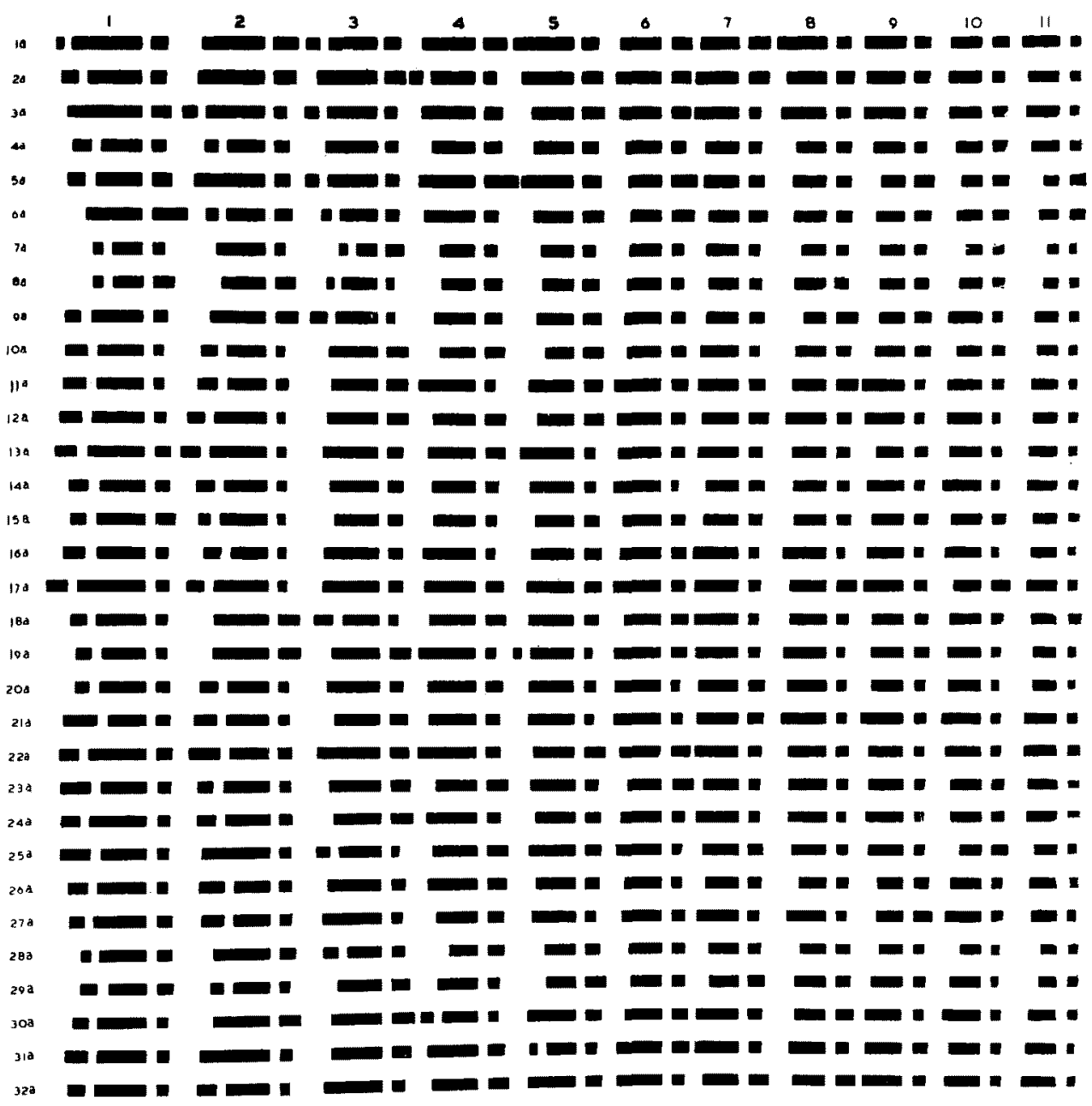

Figs. 1a-32a. Idiogram of somatic karyotypes of 32 varieties of Phaseolus mungo L.

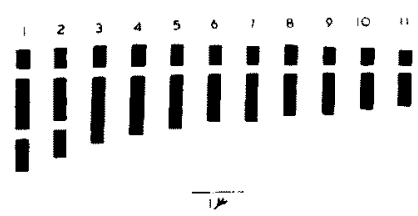

Fig. 33. Idiogram of an average karyotype of Phaseolus mungo L.

chromosome length reveals that the variety $T-77$ has the shortest $(0.67 \mu)$ and the Local Bihar has the longest chromosomes $(2.78 \mu)$ in their somatic cells as compared with the other varieties.

The striking similarities in the karyomorphology of 30 out of 32 varieties are in their first chromosome which is satellited having a subterminal primary constriction. For at least 20 varieties the second chromosome reveals a secondary constriction with subterminal primary constriction. The rest of the chromosomes 
are found either with median or submedian primary constriction but proportionately submedian primary constrictions are recorded for more number of chromosomes in a large number of varieties. However, the exceptions are the varieties No. 15-Local, No. 85 and T-27 where the first one shows 9 medians and the latter two reveal 9 submedians. An average karyotype (Fig. 33) drawn by utili-

Table 2. Karyotype formula of thirty two varieties

\begin{tabular}{|c|c|c|}
\hline $\begin{array}{l}\text { Sl. } \\
\text { no. }\end{array}$ & $\begin{array}{c}\text { Varietal } \\
\text { name }\end{array}$ & Karyotype formula \\
\hline 1. & $\mathrm{~T}-122$ & $1(\mathrm{~A}, \mathrm{St} . \mathrm{Sc})+.1(\mathrm{~A} . \mathrm{Sm})+$.1 (A.Sm.Sc.) $+3(\mathrm{~B} . \mathrm{M})+$.5 (B.Sm.) \\
\hline 2. & L41-13 & $1($ A.St.Sc. $)+2($ A,Sm. $)+1$ (B.St.Sc. $)+2($ B.M. $)+5($ B.Sm. $)$ \\
\hline 3. & Pusa-1 & 1 (A.Sm.) +2 (A.St.Sc.) +2 (B.M.) +6 (B.Sm.) \\
\hline 4. & 91-Local & 1 (A.St.Sc.) +1 (B.Sm.Sc.) +3 (B.M.) +6 (B.Sm) \\
\hline 5. & 9-Local & 2 (A.Sm.Sc.) +1 (A.Sm.) +1 (A.M. $)+1$ (B.Sm.) $+5($ B.M. $)+1$ (C.M) \\
\hline 6. & 15-Local & 1 (A.M.) $+2($ B.Sm.Sc. $)+8$ (B.M.) \\
\hline 7. & $\mathrm{~T}-77$ & 2 (A.Sm.Sc.) +4 (B.M.) +3 (B.Sm.) +2 (C.M.) \\
\hline 8. & No. 40 & 1 (B.Sm.Sc.) +1 (B.St.Sc. $)+6($ B.M. $)+1$ (C.M. $)+2($ B.Sm. $)$ \\
\hline 9. & No. 73 & 1 (A.St.Sc.) +1 (B.St.Sc.) +5 (B.Sm.) +4 (B.M.) \\
\hline 10 . & Mashl-1 & $1($ A.St.Sc. $)+1$ (B.St.Sc. $)+4($ B.M. $)+4($ B.Sm. $)+1($ C.Sm. $)$ \\
\hline 11. & No. 63 & 2 (A.St.Sc.) +2 (B.M.) +7 (B.Sm.) \\
\hline 12. & No. 54 & 2 (A.St.Sc.) +4 (B.M.) +5 (B.Sm.) \\
\hline 13. & $T-65$ & 2 (A.St.Sc.) +7 (B.Sm.) $+2($ B.M. $)$ \\
\hline 14. & No. 32 & 2 (A.St.Sc.) +1 (B.M.) +8 (B.Sm.) \\
\hline 15. & No. 16 & 1 (A.Sm.Sc.) +1 (B.St.Sc.) +5 (B.M.) +4 (B.Sm.) \\
\hline 16. & No. 85 & 1 (A.St.Sc.) +1 (B.St.Sc.) +9 (B.Sm.) \\
\hline 17. & Local Bihar & 2 (A.St.Sc.) +7 (B.Sm.) +2 (B.M.) \\
\hline 18. & No. 103 & 1 (A.St.Sc.) +1 (A.Sm. $)+1$ (B.Sm.Sc. $)+3($ B.M. $)+5($ B.Sm. $)$ \\
\hline 19. & No. 100 & 1 (A.St.Sc.) $+1($ A.Sm. $)+1$ (B.St.Sc. $)+6($ B.Sm. $)+2($ B.M. $)$ \\
\hline 20. & No. 38 & 1 (A.St.Sc.) +1 (B.St.Sc.) $+8($ B.Sm. $)+1($ C.Sm. $)$ \\
\hline 21. & No. 124 & 2 (A.St.Sc.) +8 (B.Sm.) +1 (B.M.) \\
\hline 22. & L35-5 & 2 (A.St.Sc.) +1 (A.Sm.) +6 (B.Sm.) $+2($ B.M. $)$ \\
\hline 23. & 7.9 & 2 (A.St.Sc.) $+7($ B.Sm. $)+2$ (B.M.) \\
\hline 24. & $\mathrm{~T}-130$ & 2 (A.St.Sc.) +2 (B.M.) +7 (B.Sm.) \\
\hline 25 . & Mash-48 & 1 (A.St.Sc.) +1 (B.St.Sc.) +7 (B.Sm.) +1 (B.M.) +1 (C.Sm.) \\
\hline 26. & No. 51 & 2 (A.St.Sc.) $+8($ B.Sm.) +1 (B.M.) \\
\hline 27. & BR-61 & 1 (A.St.Sc.) $+1($ B.St.Sc. $)+8($ B.Sm. $)+1$ (B.M.) \\
\hline 28. & No. 55 & 1 (A.Sm.Sc.) +1 (B.Sm.Sc. $)+3($ B.Sm. $)+4$ (B.M. $)+1($ C.M. $)+1($ C.Sm. $)$ \\
\hline 29. & MK-18 & 1 (A.Sm.Sc.) +1 (B.St.Sc.) +4 (B.Sm.) +4 (B.M.) +1 (C.M.) \\
\hline 30. & No. 20 & $1($ A.St.Sc. $)+1($ A.Sm. $)+1($ B.St.Sc. $)+2($ B.M. $)+6($ B.Sm. $)$ \\
\hline 31. & $\mathrm{~T}-27$ & 1 (A.St.Sc.) +1 (A.St.) +1 (B.St.Sc.) +8 (B.Sm.) \\
\hline 32 . & $\mathrm{T}-9$ & 2 (A.St.Sc.) +7 (B.Sm.) +2 (B.M.) \\
\hline
\end{tabular}

zing arithmatic mean of the individual chromosome of the whole somatic complement for all the varieties however, reveal a different picture which corresponds to the karyotypes of the varieties No. 85 and T-27. That is, chromosome number one is satellited with subterminal primary constriction followed by the second chromosome with secondary constriction and subterminal primary constriction. The rest of the chromosomes show submedian primary constriction. Dutta (1975) on sweet pea also utilized mean values and found similar features. 
The $\mathrm{TF} \%$ for 19 varieties is found to be in a close range of 24.31 to 27.82 and the varieties under this range have more or less a symmetrical karyotypes. The other 13 varieties have shown comparatively an asymmetrical karyotypes with $\mathrm{TF} \%$ ranging from 28 to 38.23 . The karyotypes in general for different species of Phaseolus have been reported as symmetrical (Sen and Chheda 1958, Dutta and Sen 1963, Krishnan and De 1965, De and Krishnan 1966, Singh and Roy 1970).

The presence of secondary constriction in two pairs of chromosomes and submedian primary constriction in a large number of chromosomes of a somatic complement for almost all the varieties apparently suggest the recent origin of these varieties. In absence of any evidence of chromosome aberrations in meiosis which is regular, it is difficult to ascertain the exact mechanism of origin of these karyotypic differences. In any case, these changes may have helped the process of evolution and the emergence of different varieties. On the other hand, the uniformity in the base number and considerable similarity in gross nature of the karyotypes suggest that gene mutation was the principal factor in evolution.

\section{Summary}

Karyotypic analysis of thirty two varieties of Phaseolus mungo L. showed reasonable differences between the varieties on chromosome length, position of primary constriction and in TF \% . Two pairs of chromosomes were secondarily constricted with subterminal primary constriction and occupy first and second positions in the somatic complement in almost all the varieties. In the rest of the chromosomes, the majority showed submedian primary constriction and few showed median constriction. An average karyotype of Phaseolus mungo L. has been suggested basing on the results included herewith and also considering the previous reports on this line.

The observation of $\mathrm{TF} \%$ ranging from 24.31 to 27.82 revealed a symmetrical karyotypes for nineteen varieties. The rest were observed to be asymmetrical with TF\% ranging from 28 to 38.23 . The importance of karyotypic differences in evolution of varieties within a species has been discussed.

\section{Acknowledgement}

The author expresses his indebtedness to Prof. A. K. Sharma, Head of the Department of Botany, Calcutta University for his kind suggestions and guidance.

\section{References}

De, D. N. and Krishnan, R. 1966. Studies on pachytene and somatic chromosome of Phaselous mungo L. Genetica 37: 581-587.

Datta, P. C. 1975. Natural variation of chromosome length and a critical assessment of the karyotype in sweet pea. Cytologia 40: 561-568.

Karpechenko, G. D. 1925. Chromosomes of Phaseolinae c.f. Chromosome Atlas of Flowering Plants. George Allen \& Unwin: London (1955). 
Krishnan, R. and De, D. N. 1965. Studies on pachytene and somatic chromosomes of Phaseolus aureus Roxb. Nucleus 8: 7-16.

Mukherji, C. 1973. Cytological investigation of certain species of Arachis. Proc. 60th. Ind. Sc. Cong. Part III Abstracts :313.

Naithani, S. P. and Sarbhoy, R. K. 1973. Cytological studies in Lens esculenta Moench. Cytologia 38: 195-203.

Rao, M. A. 1929b. Cytology of some crop plants of South India. J. Indian Bot. Soc. 8: 126.

Sen,N. K. and Chheda, H. R. 1958. Colchicine induced tetraploids of five varities of black gram. Ind. J. Genet, and Pt. Br. 18: 238-248.

Sharma, A. K. and Sharma, A. 1972. Chromosome Techniques: Theory and Practice. 2nd Edi, Butterworths, London, University Park Press.

Singh, A. and Roy, R. P. 1970. Karyological studies in Trigonella, Indigofera and Phaseolus. Nucleus 13: 41-54.

Sinha, S. S. N. and Acharia, S. S. 1972. Karyotype analysis in some varieties of Lens culinaris. Cytologia 37: 673-683. 